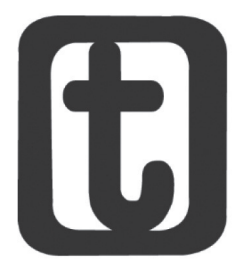

\title{
BRESSER-PEREIRA E O PACTO NEODESENVOLVIMENTISTA
}

\author{
BRESSER-PEREIRA AND THE NEW DEVELOPMENTALIST PACT
}

\section{Mariana Pfeifer}

\section{RESUMO}

O presente ensaio tem por objetivo analisar o Novo Desenvolvimentismo mediante o resgate do pensamento do economista Luis Carlos BresserPereira. Identificou-se que sua proposta apresenta elementos que, lançados na sociedade brasileira do século XXI, entra na disputa hegemônica e busca construir um novo pacto social, que denomino de Pacto Neodesenvolvimentista. Segundo as estratégias de Bresser-Pereira, este pacto pressupõe a construção de um acordo nacional dirigido pelo segmento dos empresários industriais nacionais e firmado entre os diferentes segmentos de classe no país. Enquanto proposta político-econômica, o Novo Desenvolvimentismo apresenta um receituário que engloba, por um lado, um conjunto de recomendações micro e macroeconômicas, e por outro, uma estratégia ideopolítica assentada em concepções relativas ao mercado, Estado, sociedade civil, classes, globalização, entre outros conceitos que lhe dão sustentação teórica e política e que evidenciam a existência de uma nova ofensiva burguesa no Brasil, agora alicerçada em outro bloco que disputa a direção da sociedade brasileira do século XXI.

Palavras-chave: Neodesenvolvimentismo. Pacto político. Estado.

\section{Abstract}

This essay intends to analyze the New Developmentalism by reading the thoughts of economist Luis Carlos Bresser-Pereira. Identifies that your proposal presents elements that, launched in the Brazilian society of XXI century, enters in the hegemonic dispute and seeks to build a new social pact, which call New Developmentalist Pact. According to 
the strategies of Bresser-Pereira, this pact requires the construction of a national agreement aimed at the segment of national industrial entrepreneurs and with the agreement between the different segments of class in the country. Being a political and economic proposal, the New Developmentalism presents a recipe that includes, on the one hand, a set of micro and macroeconomic recommendations, and on the other, a politic and ideological strategy seated in conceptions concerning the market, state, civil society, classes, globalization, and other concepts that give theoretical and politic support which demonstrate the existence of a new bourgeois offensive in Brazil, now rooted in another block that dispute the direction of the Brazilian society of the XXI century.

Keywords: Neo-developmentism. Political pact. State.

Submetido em 24/10/2013

Aceito em 12/01/2014

\section{INTRODUÇÃO}

Os debates neodesenvolvimentistas formam uma agenda recente fruto da virada do século XXI e que vem tomando densidade e amplitude teórica e política no cenário brasileiro, em especial, sob a escrivaninha do economista brasileiro Luiz Carlos Bresser-Pereira. As reformas neoliberais não cumpriram suas promessas de desenvolvimento: além do quadro de desemprego e de baixos salários legado aos diversos segmentos da classe trabalhadora, excluiu o empresariado produtivo local dos altos índices de rentabilidade, lucratividade e concentração que foram auferidos pelos rentistas nos anos áureos do neoliberalismo, e que representou o envio de grande parcela do produto interno bruto dos países latino-americanos às improdutivas e parasitárias frações financeiras internacionais. Não por acaso, as explicações neodesenvolvimentistas acerca do baixo crescimento dos países latino-americanos, alicerçadas em críticas ao neoliberalismo, agradam amplos setores da sociedade brasileira, a direita e a esquerda, desde os empresários nacionais que não conseguem atingir os níveis de crescimento e lucratividade desejados, até setores da esquerda, críticos ao neoliberalismo, classes trabalhadoras e pauperizadas que sofrem com as expressões da questão social. 
Por um lado, à primeira vista os debates mais acalorados em torno do Novo Desenvolvimentismo ${ }^{1}$ efetivamente se esbaldam sobre suas análises e proposições micro e macroeconômicas. Economistas brasileiros entusiastas da corrente vêm contribuindo com estudos e apontando por onde andam as tendências de crescimento no Brasil e em outros países. Suas pesquisas robustecem o Novo Desenvolvimentismo de argumentos econômicos ressaltando suas qualidades em relação às políticas neoliberais e as políticas dos tempos do nacional-desenvolvimentismo, esforçando-se em demonstrar suas semelhas e diferenças. Por outro lado, e tão púbere quanto seus propositores e entusiastas, também se vê como contraponto muitos economistas e críticos como Rodrigo Castelo (2012; 2013); Reinaldo Gonçalves (2012); Plínio de Arruda Sampaio Júnior (2012) e Ana Elizabete Mota (2012), apontando os limites das proposições neodesenvolvimentistas, tanto no que se refere aos equívocos das recomendações econômicas, quanto a sua redução ao projeto do capital. Todavia, a crítica ao neodesenvolvimentismo tem se esquecido de se debruçar sobre o seu principal intelectual: Bresser-Pereira.

A partir do estudo mais minucioso das produções de BresserPereira acerca do que denominou de Novo Desenvolvimentismo, logo é possível enxergar um escopo político-ideológico na proposta: trata-se, afinal, de uma estratégia para a recomposição capitalista nacional! Nas suas obras, textos e notas de jornal, Bresser-Pereira não se furta em tratar o Novo Desenvolvimentismo como uma solução para a retomada do desenvolvimento econômico tanto no Brasil quanto nos países de médio desenvolvimento $^{2}$. O economista constrói um arsenal de definições e

1 Ressalto que Bresser-Pereira e seus seguidores não utilizam o termo "neodesenvolvimentismo". Essa forma de abordar essa corrente teóricopolítica vem sendo utilizada pelas linhas críticas. O economista e seus entusiastas se utilizam das terminologias: "Novo Desenvolvimentismo" e "novodesenvolvimentistas". Neste texto, utilizo essas últimas terminologias sempre que me refiro às ideias de Bresser-Pereira, e uso neodesenvolvimentismo quando traço as minhas considerações.

2 Bresser-Pereira considera países de médio desenvolvimento aqueles países com renda média que completaram suas revoluções capitalistas, isto é, países que tenham um Estado nacional e que sejam industrializados e que, "agora dotados de uma ampla classe assalariada, e das instituições básicas necessárias para o crescimento econômico, os países devem provar que são capazes de continuar 
conceitos que robustecem o Novo Desenvolvimentismo de densidade sociopolítica e ideológica e que parecem ter potencialidade do ponto de vista da construção de hegemonia, não somente pelo seu acervo conceitual, mas principalmente, pelo conteúdo que sustenta e que acaba por responder aos diversos e contraditórios questionamentos e demandas.

Afirmando ser filiado à teoria econômica do desenvolvimento, à teoria estruturalista latino-americana’, à economia política clássica e marxista e à teoria macroeconômica keynesiana - que é, segundo ele, por onde andam as bases do seu Novo Desenvolvimentismo - Bresser-Pereira tem no neoliberalismo seu adversário teórico e político. Não obstante a crítica macroeconômica e ideológica que faz ao neoliberalismo, que segundo Bresser-Pereira, tem levado a economia do país à "quase-estagnação" desde 1980, sua proposta política e sua teoria econômica subjacente estão definitivamente fincadas na sociabilidade capitalista, de onde, segundo ele não há como escapar, apenas há possibilidades de encontrar um "terceiro discurso". Entende que o "capitalismo é vitorioso e organiza toda a terra em Estadosnação que competem entre si através de suas empresas, mas há muitas formas de capitalismo, mais ou menos dinâmicas, mais ou menos garantidoras de liberdade, mais ou menos justas" (BRESSER-PEREIRA, 2007, p.17). O ecletismo teórico e metodológico a que recorre parece transcender a corrente pós-moderna imperante nas ciências sociais, econômicas e humanas na contemporaneidade, combinando perspectivas extremante contraditórias ao assegurar utilizar-se do "método histórico-dedutivo"

a crescer rapidamente e gradualmente chegar aos níveis de crescimento dos países ricos" (BRESSER-PEREIRA, 2010c, p.3).

3 Bresser-Pereira cunhou de "teoria estruturalista do desenvolvimento" o pensamento econômico que foi dominante na América Latina durante as décadas de 1940 a 1960. A escola de pensamento econômico chamada pela literatura de "teoria econômica do desenvolvimento" é aquela composta pelos economistas que foram os pioneiros nos debates em torno do desenvolvimento, tais como Rosenstein-Rodan, Arthur Lewis, Ragnar Nurkse, Gunnar Myrday, Hans Singer, Albert Hirschman, Raul Prebich e Celso Furtado. O adjetivo "estruturalista" é comumente utilizado na literatura econômica para designar o pensamento latino-americano que se desenvolveu em torno dos dois últimos, Raul Prebich e Celso Furtado, e da Cepal. A denominação "teoria estruturalista do desenvolvimento" utilizada por Bresser-Pereira (2012, p. 25) se justifica pelo fato do economista considerar que "foram todos estruturalistas". 
que, segundo ele, "foi o método que Adam Smith e Marx usaram para compreender a transformação econômica fundamental que foi a revolução capitalista, ou que Keynes adotou [...] ao formular o primeiro modelo macroeconômico de uma economia monetária" (BRESSER-PEREIRA, 2007, p.21). Do ponto de vista do método, Bresser-Pereira (2009, p.11) assegura construir sua estratégia neodesenvolvimentista "como um 'tipo ideal' no sentido weberiano" observando os países asiáticos dinâmicos e suas altas taxas de crescimento. Neste sentido, como não poderia deixar de ser, sua estratégia neodesenvolvimentista funda-se igualmente num ecletismo difícil de ser decifrado, no entanto consegue com majestade garantir o caráter conservador de sua proposta.

Este artigo busca realizar uma revisão crítica marxista e gramsciana acerca do escopo político da estratégia neodesenvolvimentista de Bresser-Pereira, onde é possível evidenciar os marcos de uma ofensiva para a constituição de um novo pacto nacional: o que chamei de Pacto Neodesenvolvimentista. Cabe ressaltar que, neste artigo, optou-se por apresentar os conceitos de BresserPereira - encontrados de forma dispersa em sua obra - de modo contextualizado ao longo das páginas que seguem, portanto, o leitor irá desvendando as ideias de Bresser-Pereira conforme avançar na leitura. Pretende-se que ao final, o leitor compreenda o que cunhei de Pacto Neodesenvolvimentista 4 para caracterizar sua estratégia hegemônica, a qual depende da construção de um novo pacto nacional.

Pode-se sumariar a proposta de Bresser-Pereira da seguinte forma: o Novo Desenvolvimentismo é uma estratégia econômica e político-ideológica voltada para o desenvolvimento econômico de países de renda média no quadro de globalização. A teoria econômica que lhe subjaz é construída por ele e cunhada de Macroeconomia Estruturalista do Desenvolvimento. Suas ideias vêm sendo desenvolvidas deste início dos anos 2000, contanto com a colaboração de grupos de economistas keynesianos e estruturalistas. Bresser-Pereira deixa claro que o Novo

4 É importante indicar que o termo "Pacto Neodesenvolvimentista" utilizado no presente texto não é empregado por Bresser-Pereira. É uma denominação que construí a partir da minha análise para representar a concepção construída por Bresser-Pereira. 
Desenvolvimentismo é uma "estratégia nacional de desenvolvimento", e a Macroeconomia Estruturalista do Desenvolvimento é a teoria econômica que sustenta tal estratégia 5 . Em conjunto, compõem-se, por um lado, de um receituário que promulga políticas micro e macroeconômicas de responsabilidade fiscal e cambial, crescimento com poupança interna e papel estratégico do Estado como indutor do desenvolvimento econômico, afirmando o terreno de sua proposição como uma alternativa ao Consenso de Washington e seu tripé centrado na taxa de juros elevada, taxa de câmbio sobreapreciada e Estado mínimo. Por outro lado, do ponto de vista ideopolítico, Bresser-Pereira apregoa que a introdução desta alternativa não pode prescindir da formulação de uma "estratégia nacional de desenvolvimento" sob a direção de uma elite composta pelo empresariado industrial nacional e em coalizão com a burocracia estatal. Tal estratégia precisa ser pactuada entre as classes sociais e ancorada no princípio nacionalista econômico advindo daquelas elites. Segundo o economista, a construção deste pacto daria início a uma nova nação na conjuntura nacional, ou seja, uma aglutinação político-cultural essencial para a fundação deste que chamo de Pacto Neodesenvolvimentista.

\section{PACTO POLÍTICO E NACIONALISMO}

Do ponto de vista histórico, Bresser-Pereira analisa o desenvolvimento econômico do brasileiro e afirma que, no período de 1920 a 1980, o Brasil era o país que apresentava maiores taxas de crescimento, e que, de 1980 a 1994, foi um dos países que menos cresceu. Indica que, a partir dos anos 2000, mormente após 2004, há uma retomada do crescimento econômico nacional, mas com taxas menores do que as registradas na década de 1970.

É importante salientar que o economista Bresser-Pereira compreende crescimento como sinônimo de desenvolvimento econômico, isto é, para ele crescimento é "um processo de transformações estruturais da economia e da sociedade que levam a padrões de vida mais elevados através da acumulação de capital

5 Bresser-Pereira relaciona esta compreensão dizendo que o nacionaldesenvolvimentismo era, igualmente, uma estratégia nacional de desenvolvimento, enquanto que as teorias keynesiana e estruturalista eram as teorias econômicas que lhes davam sustentação. 
e da incorporação do progresso técnico na produção" (BRESSERPEREIRA, 2007, p.25), em outras palavras, "há desenvolvimento econômico quando a renda por habitante cresce em função do aumento da produtividade e o bem-estar da população melhora" (BRESSER-PEREIRA, 2007, p.65). Bresser-Pereira (2007, p.25) importa-se em indicar que, para ele, desenvolvimento significa "o resultado final do desenvolvimento econômico, social, político e ambiental, ou seja, o desenvolvimento voltado para os quatro grandes objetivos políticos das sociedades modernas: o bem-estar, a justiça social, a liberdade e a proteção da natureza". O desenvolvimento coloca-se como o ocaso, derradeiro, a ser alcançado em última instância após o gradual processo de crescimento e desenvolvimento econômico, este que, segundo o economista, nem sempre é necessariamente justo, democrático e com preservação ambiental, mas que garantidas as condições necessárias para que empresários invistam, inovem, realizem lucros e voltem a inovar, ao final e enfim, classes trabalhadoras poderão participar dos frutos deste desenvolvimento. E, ainda, nos alerta Bresser-Pereira (2009, p.54): "embora o desenvolvimento possa, em curto prazo, ocorrer à custa da justiça social e da proteção ambiental, em médio prazo a correlação positiva aparecerá, porque a justiça social e os defensores do meio ambiente receberão maior poder com o crescimento econômico". É, portanto, voltada ao crescimento econômico que sua obra neodesenvolvimentista se presta, como um caminho a ser percorrido na inevitável sociedade de mercado.

Bresser-Pereira demonstra ser um estrategista liberal e nacionalista. Sua grande preocupação é encontrar alternativas para a retomada do desenvolvimento econômico nacional a partir da inserção competitiva do país no quadro de competição do mercado global e, com isso, lograr novamente altas taxas de crescimento que superem a atual situação de quase-estagnação decorrente da subordinação do país aos ditames de Washington. Neste sentido, Bresser-Pereira não se furta de indicar aos seus companheiros, e mais diretamente endereçado à classe industrial 
brasileira, um caminho de coalizões políticas e acordos entre classes extremamente necessários para o rompimento do ciclo da ortodoxia convencional ${ }^{6}$ no Brasil - seu adversário principal -, e para a construção de uma outra estratégia nacional de desenvolvimento: o seu Novo Desenvolvimentismo. Critica os economistas e formuladores da política econômica brasileira acusando-os de subordinarem-se "aos diagnósticos e recomendações vindos do Norte" (2007, p.255), assim como os denuncia pela falta de espírito republicano coerente aos interesses nacionais brasileiros.

A proposta político-estratégica bresserniana de construção de um novo capitalismo para o Brasil, o "terceiro discurso", parte do diagnóstico que traça do país no século XX. Bresser-Pereira (2007, p.257) afirma empiricamente sua opção nacionalista indicando que o que tornou o país capaz de passar da condição de uma economia agrária para uma economia industrial foi o espírito nacionalista presente no período de 1930 a 1960, particularmente no governo do estadista Getúlio Vargas, e no período militar a partir de 1964 que, mesmo com a aliança com os Estados Unidos, segundo ele, continuou sendo nacionalista. Todo este período, cujo consenso nacional esteve firmado em torno das ideias de nação e de desenvolvimento econômico é o que Bresser-Pereira nominou de Ciclo Nação e Desenvolvimento (o qual abarca o período de 1930 até 1980), sob o qual transcorreram duas coalizões políticas nacionais denominadas por ele de Pacto NacionalDesenvolvimentista, que vai de 1930 até o golpe militar; e, o Pacto Burocrático-Autoritário de 1964 a 1977.

Efetivamente, a concepção de nação parece estar no centro de sua proposta político-ideológica. Bresser-Pereira toma de Ernest Gellner a compreensão segundo a qual não é a existência de uma nação que supõe a existência do nacionalismo, mas é o nacionalismo de uma elite política que cria uma nação. O nacionalismo não estaria encilhado na existência de uma identidade cultural ou no sentimento de pertencimento social ou cultural. O nacionalismo de Bresser-Pereira tem outro conteúdo

6 Bresser-Pereira chama de ortodoxia convencional o conjunto das recomendações do Consenso de Washington e das agências multilaterais como o Banco Mundial e o Fundo Monetário Internacional (FMI). 
político-ideológico: "é a ideologia de um povo que busca autonomia em relação aos vizinhos ou aos impérios para poder construir ou consolidar sua nação e seu Estado" (BRESSER-PEREIRA, 2013, p.14). O economista trabalha com uma concepção de nacionalismo econômico, ou seja, aquele que está orientado em primeira instância para os interesses econômicos nacionais num quadro global de competição capitalista, segundo ele, "um nacionalismo democrático, liberal, social e republicano” (BRESSER-PEREIRA, 2007, p.279). Quando estendido no corpo social, o espírito nacionalista seria capaz de criar uma solidariedade indiferenciada entre os contraditórios segmentos de classe no interior de um país e de levar a sociedade como um todo a "adotar critérios nacionais para tomar decisões políticas, sobretudo aquelas que envolvem política econômica e reforma institucional" (BRESSER-PEREIRA, 2009, p.85). É desta forma que seria possível a constituição de uma verdadeira Nação. A Nação bresserniana subjaz à construção de um consenso nacional que aglutina as classes em torno da ideia nacionalista de compartilhamento de interesses, de uma história e de um destino comuns e, para isso, a sociedade "precisa ter objetivos comuns, dentre os quais o principal, em termos históricos, é o desenvolvimento" (2009, p.83). O conceito de Nação de Bresser-Pereira refere-se a "sociedade politicamente organizada e voltada para a autonomia nacional e o desenvolvimento" (BRESSER-PEREIRA, 2013, p.13). Tal desenvolvimento, todavia, depende da capacidade da Nação de utilizar o Estado como instrumento de ação coletiva. Assim, para o economista, o estabelecimento de um acordo nacional entre as classes é o que dá origem a Nação. Este acordo não eliminaria os conflitos internos entre as classes, todavia Bresser-Pereira afirma que esses conflitos não são "suficientemente fortes para impedir que a nação trabalhe em conjunto" (2009, p.70), o espírito de solidariedade e de compartilhamento deve prevalecer!

Sob a hegemonia desta ideia de Nação, o país teria enfim condições de tomar as decisões nas "próprias mãos" e "pensar com as próprias cabeças", único meio de libertar-se da subordinação colonial e/ou imperialista. Bresser-Pereira considera que a construção de uma "verdadeira Nação" é o único caminho ideopolítico para a efetivação de uma estratégia nacional cujo objetivo 
concentra-se no desenvolvimento econômico. No cenário atual, somente uma Nação forte e coesa teria condições para defender os interesses, a autonomia, o mercado, as instituições e a cultura nacionais diante do quadro global composto por Estados-nação em constante jogo de competição, exploração e dependência. Seu apelo ao espírito nacionalista tem por objetivo libertar o país das amarras e tutela dos países ricos, especialmente da ortodoxia convencional (BRESSER-PEREIRA, 2003).

O economista não se furta em diferenciar para o leitor de sua estratégia neodesenvolvimentista os conceitos de povo, sociedade civil e Nação com os quais trabalha, sendo que este último é, para ele, um conceito mais amplo e teria um "sentido econômico mais claro". Em suas palavras:

Em uma sociedade moderna, temos, fora do Estado, três maneiras pelas quais essa sociedade se organiza politicamente: o "povo", que é o conjunto de cidadãos com direitos iguais e igual poder (para cada cidadão, um voto); a "sociedade civil", na qual o poder desses cidadãos é proporcional ao comando de que cada um dispõe em função da sua capacidade de organização, de seu dinheiro e de seu conhecimento; e a "nação", que é essa mesma sociedade civil, mas pretende abranger todos os cidadãos e tem uma conotação de classe e uma conotação internacional - não exclui os conflitos internos, mas implica um acordo nacional, um acordo entre as classes, quando se trata de competir internacionalmente e lograr desenvolvimento econômico (BRESSERPEREIRA, 2007, p.268).

Pode-se observar claramente em seu conceito de sociedade civil a articulação entre poder político, econômico e cultural. Bresser-Pereira não engloba neste conceito a totalidade da população, mas tão somente uma parcela que seria "apta a organizar-se e comandar". Ao povo, o poder restringe-se ao momento do voto, todavia este pertence à Nação sob o auspício do grande acordo nacional e submetido às propaladas capacidades de organização, de dinheiro e de conhecimento da sociedade civil. Do ponto de vista ético-político, a sociedade civil de Bresser-Pereira volta-se aos interesses da burguesia industrial nacional. Para o 
economista, o espaço da construção hegemônica parece estar no âmbito do seu conceito de Nação, onde ocorreria o grande acordo nacional aglutinando povo e sociedade civil. Já sua sociedade civil compõe-se do segmento dominante, estes sim detentores de capacidades organizativas, econômicas e culturais, os quais igualmente necessitam formar um consenso entre si, portanto, também um espaço de hegemonia, mas restrito ao grupo que quer se lançar a direção intelectual e moral. Seu conceito de sociedade civil se insere como campo fundamental da construção de consensos, não obstante, um consenso em torno de sua estratégia neodesenvolvimentista. Em seu vocábulo:

para tornar o novo desenvolvimentismo a política econômica do país, é fundamental convencer sua sociedade civil - ou seja, a sociedade politicamente organizada formada por empresários, classes médias intelectuais, organizações corporativas e organizações de advocacia política (BRESSER-PEREIRA, 2010b, p. 70).

Neste sentido, é no escopo da sociedade civil bresserniana que os empresários industriais nacionais, os políticos e formuladores de políticas econômicas devem alçar legitimidade. Ao povo, o convencimento é necessário, entretanto, absolutamente secundário: "a rigor seria preciso convencer o povo - a massa dos eleitores - mas nas democracias imperfeitas de que dispõe os países esse povo tem pouco poder" (BRESSER-PEREIRA, 2010b, p. 70). A centralidade do conceito de Nação igualmente se expressa em sua concepção de alienação, que seria a ausência da Nação. Bresser-Pereira (2007, p.69) formula esta ideia ao analisar o impacto da avalanche neoliberal sobre o Brasil: "uma crise que poderia ter sido temporária, acabou levando as elites brasileiras, no final dos anos 1980, a se alienarem, perderam o conceito de Nação e se renderam ao pensamento hegemônico".

Bresser-Pereira indica a eleição de Collor de Mello como o marco final dos pactos nacionalistas na historiografia brasileira e início da rendição ao neoliberalismo - segundo ele, uma ideologia antinacional. A coalizão atualmente dominante seria formada pelo que Bresser-Pereira denomina de Pacto Liberal-Dependente, o qual deixou de fora do poder os empresários industriais e 
implementou medidas contra a indústria nacional, a exemplo da desmedida abertura comercial e de contas de capital. O Pacto Liberal-Dependente seria constituído dos "rentistas, que se beneficiam dos altos juros pagos pelo Estado, dos agentes do setor financeiro [...] e dos proprietários de empresas de serviços públicos operando em situação de monopólio ou quase-monopólio" (BRESSER-PEREIRA, 2007, p.260). Em função de seu caráter globalista7, o Pacto Liberal-Dependente contaria ainda com o apoio das elites e governos do Norte, assim como das multinacionais que estão instaladas no Brasil. Neste contexto, Bresser-Pereira avalia que o Brasil voltou a uma condição semicolonial, transferindo os centros de decisão para fora do país e submergindo a possibilidade de construção de um grande acordo entre as classes no interior do país. Bresser-Pereira censura este Pacto por utilizar-se da estratégia ideológica neoliberal que "demoniza" o Estado. Ao localizar a estrutura estatal e seus burocratas como os grandes inimigos do crescimento, da eficiência gerencial pública e da estabilidade econômica, o Pacto Liberal-Dependente acabou incorrendo no enfraquecimento da coalizão básica de uma Nação, isto é, o acordo político entre os empresários nacionais e a burocracia do Estado - base imprescindível de apoio a uma política macroeconômica voltada aos interesses da indústria nacional.

Bresser-Pereira compreende a relação entre as classes como um jogo de barganha e troca de benefícios. Marca novamente seu terreno no campo do projeto burguês alertando as classes empresariais nacionais acerca de duas possibilidades que podem ter ao conquistarem aliados de um lado ou a outro. Veja-se a seguinte passagem:

7 Oglobalismo seria a ideologia que proclama a perda de relevância e de autonomia dos Estados-nação no quadro da globalização e que prega a centralidade do livre mercado, comercial e financeiro (BRESSER-PEREIRA, 2006a). Cabe ressaltar que, para Bresser-Pereira (2009, p.33), nas sociedades em desenvolvimento, a ideologia globalista somente "é útil para limitar manifestações nacionalistas naquelas sociedades e para levar suas elites dependentes a se subordinarem às elites dos países ricos". O globalismo seria a ideologia da globalização cujo conteúdo afirma que os Estados passam a ter um papel irrelevante, que o mercado é a instituição que se torna dominante na coordenação dos sistemas econômicos e, pressupõe que o capitalismo norte-americano é o único caminho possível para o desenvolvimento. 
Para a classe capitalista de um país em desenvolvimento como o Brasil, a opção política fundamental está em saber se deve se aliar aos trabalhadores e às classes médias profissionais que constituem seu mercado interno, ou às elites dos países ricos. No primeiro caso ela tem que aceitar maiores salários diretos e indiretos, na forma de serviços públicos de educação, saúde e assistência social oferecidos aos trabalhadores e à classe média profissional. Em compensação, tem um mercado interno maior e mais seguro para realizar lucros e os governos que a representam são dotados de maior legitimidade política. No segundo, as elites capitalistas locais podem, internamente, aceitar salários diretos e indiretos menores e internacionalmente lograr uma recepção mais amigável, embora jamais igual, da parte das elites correspondentes nos países ricos, mas perdem as vantagens da primeira opção. No caso de um país grande como o Brasil, que possui um respeitável mercado interno, para a classe capitalista como um todo a segunda opção só fazia sentido na época da guerra fria, quando havia um medo real do comunismo. Hoje ela apenas faz sentido para os rentistas. Mesmo para o setor financeiro é discutível que haja vantagem, porque, especialmente os grandes bancos de varejo, dependem do crescimento do mercado interno para crescer (BRESSER-PEREIRA, 2007, p.258-259).

O tratamento tecido por Bresser-Pereira aos diferentes segmentos de classe torna-se contraditório por referenciar, por um lado, uma perspectiva unitária e de solidariedade entre os segmentos, como ele por vezes sustenta ao construir a ideia de Nação. Por outro e ao contrário, incorre na fragmentação dos interesses divergentes dos diversos segmentos de classe, o que o leva a colocar o Estado como mediador desses conflitos através da destinação do Fundo Público. Em suas palavras: "o fato é que o aparelho do Estado brasileiro funciona como uma enorme agência de transferência de renda" (BRESSER-PEREIRA, 2007, p. 265). Além da captura dos recursos públicos efetuada pelo bloco dominante, o economista afirma que os setores que se encontram excluídos do pacto dominante igualmente podem "receber a sua parte", tal como o conjunto de despesas públicas capturadas 
pelos lucros monopolistas das grandes empresas prestadoras de serviços públicos, os grandes empresários do ramo dos serviços e indústrias e agricultores que tem empréstimos e financiamentos a juros subsidiados pelo BNDES e Banco do Brasil, até a universidade pública e gratuita como um "benefício" da classe média e os programas de renda mínima destinados à população pobre - estes últimos, segundo ele, são as únicas despesas estatais legítimas.

Neste horizonte, a estratégia neodesenvolvimentista de Bresser-Pereira afiança que o quadro de quase-estagnação reinante da atualidade assinala o esgotamento do Pacto LiberalDependente, e suas críticas centram-se no abandono das ideias de Nação e de desenvolvimento econômico e pela subordinação aos preceitos da ortodoxia convencional. Diante deste esgotamento, o economista afirma que já existem indícios do surgimento de um novo pacto no contexto atual, todavia não dá um nome a esta pacto como fez com os demais, tão só indica sua vinculação à ideologia novo-desenvolvimentista. Tomei então a liberdade a denominá-lo de Pacto Neodesenvolvimentista.

Bresser-Pereira sugere aos seus companheiros que a oportunidade para a construção do novo pacto está na mudança de posição dos empresários industriais, que depois de muitos anos de hegemonia política, entre 1930 e 1987, perderam poder diante da coalizão neoliberal. Analisando a atuação dos empresários articulados em torno, por exemplo, da Federação das indústrias do Estado de São Paulo (Fiesp), Confederação Nacional das Indústrias e do Instituto de Estudos para o Desenvolvimento Industrial (IEDI), Bresser-Pereira afirma que, os empresários industriais

começam, porém, a se dar conta de que o que se montou no Brasil foi um processo de captura do patrimônio do Estado, de violência contra os direitos republicanos dos cidadãos, que beneficia menos a burocracia do Estado e mais os rentistas, o setor financeiro e as empresas multinacionais; que, como os trabalhadores e a burocracia do Estado, também eles, empresários industriais, e, mais amplamente, todo o empresariado dos setores produtivos estão excluídos do pacto [Liberal-Dependente] atual (BRESSER-PEREIRA, 2007, p.272-273). 
Com este discurso - propugnado por ele e por seus seguidores, tanto no meio acadêmico quanto no meio político, através dos seus diferentes aparelhos privados de hegemonia -, BresserPereira faz um chamamento indiferenciado a toda sociedade brasileira, com argumentos econômicos e político-ideológicos que agradam empresários e classes trabalhadoras, cada qual com seus interesses e demandas, seja por incentivos ao desenvolvimento empresarial nacional, seja por incluir as demandas sociais e de consumo das classes trabalhadoras, mesmo que como consequência dos frutos dos primeiros. Bresser-Pereira mostra o papel ardiloso da aglutinação dos diferentes segmentos de classe para a conformação do novo Pacto Neodesenvolvimentista, cada qual com suas insatisfações e prejuízos frutos da ortodoxia convencional. Registra que a classe média profissional formada por "administradores, técnicos e intelectuais que constituem o capital de conhecimento de uma Nação" são um "parceiro estratégico" e que os trabalhadores "deverão naturalmente participar" deste acordo nacional para o desenvolvimento (BRESSER-PEREIRA, 2007, p.276).

Contudo, a estratégia neodesenvolvimentista de BresserPereira marca claramente a classe que deve liderar o processo: os empresários industriais nacionais, estes em coalizão com a burocracia do Estado. Como membros natos desta coalizão, o economista coloca os empresários da indústria de transformação nacional; já em relação aos ligados à indústria de mineração e ao agronegócio - considerados por ele como um segmento muito indefinido, pois ora tange ao lado do Norte, ora o segmento é solidário a indústria nacional -, sua articulação à nova coalizão dependerá da sua decisão em relação à taxa de câmbio, a qual, mantida dentro dos padrões da ortodoxia convencional, se lhes tornam extremamente rentável. O economista faz uma profunda análise das elites brasileiras e mostra o que considera serem seus erros e fragilidades. Tem como linha mestra de argumentação o fato das elites nacionais empresariais, políticas e intelectuais serem "nacional-dependentes", faltando-lhes, portanto, o espírito nacionalista e a hegemonia da Nação que os constitua enquanto uma legítima burguesia nacional, e conceitua: "uma 
burguesia nacional, ou seja, uma classe empresarial comprometida com os interesses nacionais" (BRESSER-PEREIRA, 2007, p.273). Para ele,

O empresário é um homem ou uma mulher com energia e vontade de realização que assume riscos e inova. Seus objetivos fundamentais são o lucro e o crescimento de sua empresa. Não são especialistas em ideias e análises gerais. Este papel, nas sociedades capitalistas, cabe aos políticos, à alta burocracia e aos intelectuais (BRESSER-PEREIRA, 2007, p.273).

\section{O NOVO DESENVOLVIMENTISMO COMO PACTO NACIONAL}

Intelectual orgânico do empresariado industrial brasileiro, Bresser-Pereira assume que para formular a estratégia do Novo Desenvolvimentismo baseou-se em duas experiências históricas que considera bem sucedidas, especialmente porque ambas adotaram estratégias nacionais de desenvolvimento. A primeira é o nacional-desenvolvimentismo brasileiro, do período entre 1930 e 1980 , quando, segundo ele, se desenvolveu uma ideologia nacionalista possibilitadora da efetivação do pacto nacional que fundou a "verdadeira Nação" e tornou o país capaz de construir e manter uma estratégia nacional de desenvolvimento. Seu reduto desenvolvimentista justifica-se, ainda, pelo seu declarado apreço pela teoria keynesiana que sustentou o período. No contexto da grande crise da dívida a partir de 1980, o fato principal para Bresser-Pereira (2009, p.81) é que "os países latino-americanos interromperam suas revoluções nacionais e viram suas nações se tornarem desorganizadas e perderem coesão e autonomia; como consequência ficaram sem uma estratégia nacional de desenvolvimento" e acabaram aceitando de forma indiscriminada todas as reformas recomendadas pela ortodoxia convencional, como a liberalização, privatização e abertura das contas de capital. Bresser-Pereira também se utilizou como segundo exemplo para justificar histórica e empiricamente a assertiva de sua estratégia neodesenvolvimentista, a experiência dos "países asiáticos dinâmicos" que, de acordo com ele, mantiveram-se em crescimento mesmo após a crise de 1980 e que, também atualmente apresentam taxas de crescimento significativas graças à adoção de uma estratégia nacional de desenvolvimento e à não subordinação 
ao receituário da ortodoxia convencional. O autor afirma que mesmo os países desenvolvidos sempre lançaram mão de estratégia nacional de desenvolvimento, e dá o exemplo da Alemanha e Japão (BRESSER-PEREIRA, 2010a).

O Novo Desenvolvimentismo de Bresser-Pereira habita o contexto da globalização. Para ele, "o capitalismo global é um sistema econômico mundial cujos componentes básicos são tanto as empresas quanto os Estados-nação soberanos" (2009, p.40). Não apenas as empresas, mas também os Estados-nação ${ }^{8}$ competem entre si buscando melhores acordos e espaços comerciais e financeiros para suas empresas nacionais. Critica as teses que advogam a perda de importância dos Estados-nação e insiste em que o que marca o capitalismo contemporâneo é justamente uma acirrada competição entre eles através de seus governantes por maiores taxas de crescimento econômico. Esta leitura está no cerne de sua teoria macroeconômica. Bresser-Pereira (2009, p.83) indica que

os governantes serão bem-sucedidos aos olhos do seu povo e internacionalmente se conseguirem alcançar maiores taxas de crescimento do que os países considerados como concorrentes diretos. A globalização é o estágio do capitalismo em que, pela primeira vez, os Estados-nação abrangem o mundo todo e competem economicamente por meio de suas empresas.

Recomenda que o país deve adotar uma política de câmbio e de juros que possibilite oportunidades para suas empresas nacionais exportarem, isto é, deve proporcionar condições para que as empresas nacionais sejam competitivas internacionalmente. Neste sentido, analisa que a globalização comercial é

8 Bresser-Pereira (2009, p.40-41) conceitua: “Os Estado-nação são entidades políticas soberanas, compostas de três elementos: uma nação, um território e um Estado. Este último, portanto, não pode ser confundido com a nação ou com o Estado-nação (ou com o governo que chefia o Estado). Enquanto a nação é um tipo de sociedade, o Estado-nação, uma unidade política e territorial, o Estado é uma instituição: é o sistema constitucional e a organização que o sustentam; é a lei e o aparelho do Estado. No capitalismo, as nações usam seus Estados como instrumentos da ação coletiva para atingir seus objetivos políticos, entre os quais está sempre a manutenção da própria soberania e o desenvolvimento econômico". 
uma grande oportunidade para que os países de renda média se desenvolvam e atinjam níveis de crescimento próximos ou superiores aos países ricos. Para Bresser-Pereira, é necessário neutralizar os aspectos negativos da globalização financeira, e diz que os Estados não devem utilizar a poupança externa - empréstimos junto aos organismos e bancos internacionais - como política de crescimento, que leva o país a contrair dívidas externas - o que beneficia, segundo ele, apenas os países ricos -, mas utilizar-se da poupança interna, isto é, recursos do próprio país para acelerar o crescimento. Aqui reside um dos elementos principais da estratégia nacional de desenvolvimento, a política micro e macroeconômica, que deve estar alicerçada nos interesses da Nação: "é a afirmação do interesse nacional nas arenas internacionais competitivas. É o nacionalismo que não tem dúvida alguma de que o dever do seu governo é defender o trabalho, o conhecimento e o capital nacionais" (BRESSER-PEREIRA, 2007, p.85).

Obviamente que este apelo à proteção dos interesses da nação pode soar para os desavisados como um discurso includente, democrático e indiferenciado. Não se pode perder de vista, que sua Nação é guiada pela elite empresarial nacional que coloca o Estado como seu instrumento de coordenação política e econômica a favor de seus próprios interesses. Bresser-Pereira localiza o trabalho - as diferentes camadas da classe trabalhadora - como fator de produção e como mercado consumidor interno, portanto, há necessidade de instruí-lo, socializá-los e aculturá-los para os interesses da indústria nacional. O neodesenvolvimentismo não é um projeto que busca a emancipação humana e o fim das desigualdades de classe. Ao contrário, toma a existência das classes e o capitalismo como naturais e inevitáveis; e concebe as relações de classe como um jogo de troca de benefícios. É uma estratégia orgânica de dominação do empresariado industrial brasileiro, buscando reconstituí-lo enquanto burguesia nacional e, para isso, quer lançar na sociedade seus valores nacionalistas e desenvolvimentistas em busca de um consenso, e quer dominar a estrutura estatal e utilizá-la como instrumento de sua predominância política e econômica. Quer alçar lucros não somente no âmbito do ávido e consumista mercado interno, mas também no competitivo mercado externo. Seu Estado deve trabalhar duro na 
constituição das condições internas de reprodução capitalista, e também deve se lançar no ambiente internacional auferindo acordos econômicos, comerciais e financeiros em prol dos interesses nacionais, isto é, dos interesses do empresariado industrial nacional. Quando esta classe enfim gozar do crescimento, lucratividade e acumulação compatíveis com as taxas dos países centrais, alcançando o catch up ${ }^{9}$ - essa é a promessa neodesenvolvimentista! -, aí sim haverá uma brecha para os interesses das classes trabalhadoras, uma nova fatia do novo bolo.

Aos pobres, isto é, os segmentos pauperizados e com inserção precária no mundo do trabalho, sua reprodução estará garantida mediante políticas focalizadas de transferência de renda, bem ao gosto do mote "combate à miséria". Não há dúvida de que o etapismo construído por Bresser-Pereira enfoca, em primeiro lugar, a retomada do desenvolvimento econômico; em segundo, os investimentos públicos para a dotação de fatores de crescimento e de infraestrutura econômica e a redução da dívida pública; e, por último, se houverem recursos, dar continuidade às políticas de caráter social e de estímulo ao emprego e à incorporação dos mais pobres na produção. Em suas palavras: "uma das razões centrais pelas quais o capitalismo ainda é a única opção para as organizações socioeconômicas é que os aumentos de produtividade podem ser compartilhados pelos trabalhadores e pela classe média sem reduzir a taxa de lucro" (BRESSER-PEREIRA, 2009, p.72). Bresser-Pereira ressalta a importância de uma "política de distribuição orientada para o consumo de massa" que envolva a classe média. Para o economista, "a ideia de mercado interno, que é central para uma visão nacional”, está presente na sua estratégia neodesenvolvimentista. O mercado seria a instituição que tem como função a coordenação e o controle dos sistemas econômicos e reflete os interesses em jogo, portanto ele reconhece que "não são instituições neutras", "não tem como critério a melhor distribuição de renda" (BRESSER-PEREIRA, 2007, p.261); “jamais é um sistema equilibrado de soma zero: sempre existem os que ganham mais" (BRESSER-PEREIRA, 2007, p.61).

9 O processo catch up na teoria econômica significa o processo segundo o qual um país de renda média alcança os níveis de desenvolvimento e crescimento econômico dos países ricos. 
Ciente das limitações do mercado, o desenvolvimentista que se intitula keynesiano proclama a necessidade de um Estado regulador como instrumento essencial do Pacto Neodesenvolvimentista.

Observe-se como o economista conceitua sua ideia de estratégia nacional de desenvolvimento na seguinte passagem:

O que é uma estratégia nacional de desenvolvimento? É um conjunto de valores, ideias, leis e políticas orientadas para o desenvolvimento econômico, que levam a criação de oportunidades para que os empresários dispostos a assumir riscos possam investir e inovar. A instituição chave ou o grupo de instituições por trás do crescimento econômico não é a garantia dos direitos de propriedade e dos contratos, como sugerem os novos institucionalistas, mas a estratégia nacional de desenvolvimento. É menos do que um projeto ou plano nacional de desenvolvimento, porque não é formal; falta-lhe um documento que descreva com precisão os objetivos ou as políticas a serem implementadas para atingir esses objetivos, porque o acordo inerente as classes sociais não tem nem texto nem assinaturas. E é mais do que um projeto ou plano nacional de desenvolvimento porque abrange informalmente $o$ conjunto da sociedade, ou uma grande parte dela; ilumina para todos um caminho a ser trilhado e estabelece certas diretrizes bem gerais a serem observadas; e, embora não pressuponha uma sociedade sem conflitos, exige um razoável consenso quando se trata de competir internacionalmente. É mais flexível do que um projeto, e leva sempre em conta as ações dos oponentes ou concorrentes. Reconhece que o fato que impulsiona o comportamento individual não é apenas o interesse nacional, mas a competição com outras nações. Uma estratégia nacional de desenvolvimento reflete tudo isso. Sua liderança cabe ao governo e aos elementos mais ativos da sociedade civil. Seu instrumento fundamental é o próprio Estado: suas normas, políticas e organização. Seu resultado, quando se estabelece um grande acordo, quando a estratégia se torna realmente nacional, quando a sociedade começa a compartilhar, frouxa mais efetivamente, métodos e objetivos, é a aceleração do desenvolvimento - um 
período durante o qual o país goza de alta renda per capta e altas taxas de crescimento dos padrões de vida (BRESSER-PEREIRA, 2010c, p.4-5).

Tal como conceituado por Bresser-Pereira, verifica-se que a estratégia nacional de desenvolvimento está assentada no campo superestrutural e, mais especificamente, na arena da hegemonia. É uma ideologia ${ }^{10}$ que precisa ser partilhada pelo corpo social e atravessada pelos diferentes segmentos de classe; porém cabe às elites empresariais nacionais elaborá-la! É, logo, um pacto ideologicamente construído e disseminado - por isso que chamo de Pacto Neodesenvolvimentista. Pela pactuação desta estratégia nacional de desenvolvimento, os empresários, técnicos do governo, trabalhadores e intelectuais articular-se-ão em uma "verdadeira Nação". O objetivo da estratégia nacional de desenvolvimento é o catch up, isto é fazer com que um país de renda média alcance o nível de desenvolvimento e crescimento econômico dos países ricos mediante sua inserção estratégica na competição global. Nesse sentido, é uma estratégia de competição nacional, construída a partir e voltada para interesses nacionais, e tem no Estado o ator que a põe em movimento. Assim, não é só no campo das concepções de mundo que a estratégia nacional de desenvolvimento transita, ele é fundamental, mas ainda, seu conteúdo deve estar presente e representado no âmbito do próprio Estado, nas leis, normas e políticas, isto é, na sociedade política.

Por fim, outros elementos da teoria bresserniana são relevantes para apreender a constituição do Pacto Neodesenvolvimentista. O Estado é compreendido por BresserPereira como um "instrumento" da "ação coletiva”, cujo caráter de classe já se desvendou vinculado ao segmento empresarial da indústria nacional. O Estado neodesenvolvimentista deve criar as condições normativas e políticas nacionais e internacionais que busquem "criar oportunidades lucrativas de investimentos para os empresários" (2009, p.47). Na esteira de sua propalada orientação keynesiana, Bresser-Pereira opõe-se ao "fundamentalismo de mercado" da ortodoxia convencional buscando mostrar

10 Para Bresser-Pereira (2007, p.281) ideologia é "um conjunto e ideias e de valores orientados para uma ação política". 
que os governos têm papel central na condução do processo de desenvolvimento econômico através

da definição de instituições necessárias ao desenvolvimento capitalista, como a garantia da propriedade e dos contratos, a proteção de indústria nacional, e os mais variados sistemas de estímulo ao investimento produtivo, e também através da institucionalização de educação pública universal que permita o aumento da produtividade da economia (BRESSER-PEREIRA, 2006b, p.205).

Veja-se que, nos seus escritos, a institucionalização de uma educação pública universal é uma das funções do Estado na dotação de condições para o aumento da produção econômica. Obviamente que sua concepção de universalização não se coloca no marco beveridgiano de prestação pública de serviços sociais com caráter público, estatal, universal e gratuito. Seu discurso está enredado na perspectiva de descentralização da política social formulada por ele já nos tempos da Reforma da Gestão Pública de 1995. A perspectiva privatista da política social se coloca na análise que Bresser-Pereira faz da intervenção estatal dos últimos anos, veja-se:

Desde 2003, assistimos à estagnação e retrocesso na esfera federal, enquanto a reforma avança nos governos estaduais e municipais. Estagnação na reforma das estruturas, com ampliação do número de organizações baseadas em formatos tradicionais - vide o aumento do número de ministérios e secretarias de Estado, a criação de sete novas universidades com o mesmo formato institucional das atuais e enrijecidas universidades públicas federais ou tentativa de impor formatos rígidos a entidades dotadas de algum grau de autonomia. $O$ retrocesso é claro quanto à organização do serviço público concursos, política salarial, extensão de benefícios a aposentados, politização dos cargos de confiança. [...] A consequência disso é o agravamento de uma tendência perversa na administração pública burocrática - a de tornar as avaliações de desempenho meramente formais, igualando todos os avaliados nos níveis mais altos (BRESSER-PEREIRA, 2007, p.110). 
O Estado de Bresser-Pereira é uma instituição voltada ao desenvolvimento econômico; "um Estado forte do ponto de vista fiscal, administrativo e de legitimidade política" (2007, p.107), não é um Estado social. Tem papel central, por um lado, na garantia da operação do mercado e, por outro em "prover as condições gerais para a acumulação de capital, como educação, saúde, transporte, comunicações e infraestrutura energética" (BRESSER-PEREIRA, 2009, p.94). O economista indica que o Estado deve investir nesses setores estratégicos para 0 crescimento econômico, mas deve contar com o setor privado nacional na promoção destes bens e serviços: "o novo-desenvolvimentismo compreende que, em todos os setores em que exista uma razoável competição, o Estado não deve ser um investidor; ao contrário, deve se concentrar em defender e garantir a concorrência" (BRESSER-PEREIRA, 2009, p.94). A política social é colocada no interior do Pacto Neodesenvolvimentista como condições gerais da acumulação capitalista, deve "ser compatível com a dotação de fatores da economia" (BRESSER-PEREIRA, 2010c, p.5) e é desejável que sua promoção se dê no âmbito da competição intercapitalista. Isto é, as políticas sociais neodesenvolvimentistas devem voltar-se, no campo da infraestrutura, para a dotação de fatores de produção e constituição de um mercado de consumo de massa interno; no campo superestrutural, para a construção ideológica da Nação. Veja-se que esta ideia está no núcleo do Pacto Neodesenvolvimentista: "um elemento da nova estratégia nacional de desenvolvimento é o da construção de uma sociedade de consumo de massa" (BRESSER-PEREIRA, 2007, p.299). Isto, verdadeiramente, já caminha a passos largos no Brasil contemporâneo.

Verifica-se, ainda que seu discurso diz ser necessário construir oportunidades para as classes médias profissionais e empresariais e aos pobres, segmentos estes que formam, por um lado, a classe profissional e trabalhadora que sustenta a mão de obra disponível no país e, por outro, constituem o grande mercado consumidor interno do Brasil. Vê-se com isso, que Bresser-Pereira compreende os diferentes segmentos de classe enquanto fatores de produção, cada qual com sua função no processo de desenvolvimento e, como parte do grande Pacto Neodesenvolvimentista, 
cada um deve compreender-se como tal e desempenhar seu papel. Nos termos no economista:

O desenvolvimento, hoje, depende de uma grande e informal aliança entre empresários do setor real, técnicos públicos e privados e trabalhadores - dos detentores, portanto, dos três fatores fundamentais do desenvolvimento econômico: capital e capacidade empresarial, conhecimento técnico e organizacional, e força de trabalho. Uma Nação só se constrói quando um acordo desse tipo existe. Um acordo que não impeça conflitos internos, mas que garanta a solidariedade básica necessária para uma Nação (BRESSER-PEREIRA, 2007, p.298-299).

\section{À GUISA DE CONCLUSÃO}

O escopo conceitual de Bresser-Pereira vai muito além do que os limites deste artigo podem resgatar. Entretanto, até aqui já é possível evidenciar que o componente superestrutural da proposta neodesenvolvimentista tem vulto e está definitivamente colocado no cenário nacional na luta pela conquista hegemônica. Isto é, compreendo que o panorama dos anos que abrem o século XXI no Brasil é marcado pela investida do projeto liberal e burguês que aqui denomino de Pacto Neodesenvolvimentista. Este vem se construindo e alargando suas bases de sustentação no país, tanto no campo ideocultural quanto no plano teórico e político, colocando-se ideologicamente enquanto um projeto alternativo ao neoliberalismo e voltado à retomada da acumulação capitalista nacional no contexto de competição e de crise do capitalismo global. Sua construção, que nasce no âmago da teoria econômica desenvolvimentista nacional, tem rebatimentos no campo da disputa hegemônica dentro do país e influenciou a direção da política econômica e da política social operadas pelos governos petistas no Brasil. A incidência nos governos petistas se assenta no aparente giro ideológico operado no seu discurso e nas suas práticas políticas, o que pode trazer as evidências e os elementos da construção do Pacto Neodesenvolvimentista no país. Assim, cabe aos pesquisadores do campo social e econômico investigar e acompanhar o desenvolvimento do Pacto Neodesenvolvimentista na sociedade brasileira, buscando evidenciar suas estratégias de reprodução e construção de consensos, sua processualidade no 
âmbito das políticas econômicas e sociais, e trazer subsídios para seu enfrentamento teórico e político.

\section{REFERÊNCIAS}

BRESSER-PEREIRA, Luiz Carlos. Retomada da revolução nacional e o novo desenvolvimentismo. In: Desenvolvimento e Crise no Brasil. São Paulo: Editora 34, 2003.

BRESSER-PEREIRA, Luiz Carlos. O novo desenvolvimentismo e a ortodoxia convencional. São Paulo em Perspectiva. v.20, n.3, p.524, jul/set, 2006a.

BRESSER-PEREIRA, Luiz Carlos. Estratégia Nacional e Desenvolvimento. Revista de Economia Política. v.26, n.2 (102), p.203-230 abr/jun, 2006b.

BRESSER-PEREIRA, Luiz Carlos. Macroeconomia da estagnação: crítica a ortodoxia convencional no Brasil pós-1994. São Paulo: Editora 34, 2007.

BRESSER-PEREIRA, Luiz Carlos. Globalização e Competição: por que alguns países emergentes tem sucesso e outros não. Rio de Janeiro: Elsevier, 2009.

BRESSER-PEREIRA, Luiz Carlos. A macroeconomia estruturalista do desenvolvimento por trás do novo desenvolvimentismo. Disponível em <http://www.bresserpereira.org.br>. Publicado em 11 jun 2010a. Acesso em 20 de agosto 2013.

BRESSER-PEREIRA, Luiz Carlos. Novo desenvolvimentismo: uma proposta para a economia do Brasil. Nueva Sociedad. Especial em português. Dez, 2010b.

BRESSER-PEREIRA, Luiz Carlos. Do antigo ao novo desenvolvimentismo na América Latina. Texto para Discussão $\mathbf{n}^{\circ}$ 274. São Paulo: EESP/FGV, Nov. 2010C.

BRESSER-PEREIRA, Luiz Carlos. A taxa de câmbio no centro da teoria do desenvolvimento. Estudos Avançados. v. 26. n. 75. Mai/ ago, 2012. 
BRESSER-PEREIRA, Luiz Carlos. Nacionalismo e novo desenvolvimentismo. In: BRESSER-PEREIRA, Luiz Carlos (org.). O Que Esperar do Brasil? Rio de Janeiro: Editora FGV, 2013.

CASTELO, Rodrigo. O novo desenvolvimentismo e a decadência ideológica do pensamento econômico brasileiro. Serviço Social e Sociedade. n.112, p.613-636, out./dez., 2012.

CASTELO, Rodrigo. O social-liberalismo: auge e crise da supremacia burguesa na era neoliberal. 1. ed. São Paulo: Expressão Popular, 2013

GONÇALVES, Reinaldo. Novo desenvolvimentismo e Liberalismo Enraizado. Serviço Social e Sociedade. São Paulo, n. 112, p. 637671, out./dez., 2012.

MOTA, Ana Elizabete (Org). Desenvolvimentismo e construção de hegemonia: crescimento econômico e reprodução da desigualdade. São Paulo: Cortez, 2012.

SAMPAIO JUNIOR, Plínio Soares de Arruda. Desenvolvimentismo e neodesenvolvimentismo: tragédia e farsa. Serviço Social \& Sociedade, n.112, v. 1, p. 672, out./dez., 2012. 